Philologica Canariensia

Revista de Filología de la Universidad de las Palmas de Gran Canaria

20 (2014), eISSN: 2386-8635

DOI: en trámite

\title{
RAZONES PARA UN “EXILIO INTERIOR”. VICENTE ALEIXANDRE Y LA GUERRA CIVIL ESPAÑOLA
}

\author{
Alejandro Duque Amusco \\ Doctor en Filología Hispánica por la Universidad de Barcelona
}

\begin{abstract}
RESUMEN
El poeta Vicente Aleixandre prestó su apoyo durante la Guerra Civil española al bando republicano, hasta que en los primeros meses de 1937 los mismos republicanos lo detuvieron y lo llevaron a la cárcel, aunque antes de las veinticuatro horas fue puesto en libertad. A partir de ese momento -y tras un intento frustrado de salir del país- se retiró de la vida pública y optó por el silencio. Acabada la guerra, mantuvo una distancia crítica con el régimen franquista e hizo cuanto le fue posible por la reconciliación entre las dos Españas. PALABRAS CLAVE: Vicente Aleixandre, guerra civil española, apoyo a la República española, intento de exilio, malade imaginaire.
\end{abstract}

\section{ABSTRACT}

The poet Vicente Aleixandre supported the Spanish Republic during the Civil War. However, at the beginning of 1937 he was arrested by the Republican army. Although he was kept in prison for less than 24 hours, upon his release he tried to leave the country. When his attempt proved unsuccessful, he withdrew from public life and he never showed his support for the Republic again. After the War, he kept his distance 
from the Franco regime and worked towards the reconciliation of the "two Spains". KEYWORDs: Vicente Aleixandre, Spanish Civil War; support of the Spanish Republic, exile attempt, malade imaginaire.

\section{PUNTO DE PARTIDA}

El asunto del que trata el presente artículo tiene como punto de partida unas páginas que di a conocer en Italia, en mayo de 1998, dentro del congreso La Spagna degli anni'30 di fronte all'Europa, celebrado en la Universidad de Salerno. Llevaban por título "Vicente Aleixandre: el imposible exilio"1. El nuevo artículo retoma, en mínima parte, ciertos datos expuestos por primera vez en aquella ocasión, algunos debidamente matizados o rectificados, pero son datos nuevos en su mayoría los que ahora se ofrecen, fruto de una labor de investigación llevada a cabo durante varios años.

Si en cierto modo la cultura es empresa colectiva, mucho más lo es la tarea de investigación. En este sentido, me resulta muy grato reconocer la ayuda prestada por dos apreciados colegas y amigos míos, especialistas en historia contemporánea, Joan Sanromà Bauló y Xavier Pardo del Campo, así como la colaboración del profesor Paulino Matas Gil, que me facilitó el acceso "a los papeles" del Archivo de la Guerra Civil de Salamanca, para llevar adelante este estudio. Gracias a la desinteresada aportación de todos ellos, pude encauzar desde el principio esta investigación con una mayor confianza en su resultado.

\section{EL IDEARIO DEL POETA}

Sabido es que en la Guerra Civil española Vicente Aleixandre apoyó desde el primer momento al gobierno legítimamente constituido en las elecciones generales de febrero de 1936. Su respaldo al bando republicano está fuera de toda duda. Antes de la guerra, su postura política, su ideología - a diferencia de Lorca, Prados o Alberti, por citar sólo a algunos compañeros de generación-, no sintió la necesidad de hacerla pública, aunque todo poeta, hasta el más reservado, siempre está diciéndonos desde su poesía qué creencias tiene, cómo piensa, quién es él en verdad. La poesía es una ventana abierta directamente al ser moral de cada autor. 
¿Qué sabemos de Aleixandre, por su poesía, antes del 36? En realidad, mucho. Sus dos obras más próximas al surrealismo, Pasión de la Tierra y Espadas como labios, plantean de manera inequívoca su rechazo a lo que podríamos llamar "el mundo social” y su asfixiante código de conducta. Pasión, de 1935, y Espadas, de 1932, dos libros cáusticos como pocos, agresivos e irónicos, son demoledores cuando dirigen su punto de mira hacia la sociedad; en especial, hacia la sociedad biempensante, a los valores de la vida burguesa y a la hipocresía de las clases acomodadas y "de buen tono". En poemas como "El vals", "Cada cosa, cada cosa", "Libertad" o "El más bello amor" (todos de Espadas como labios), los ataques a las convenciones sociales son permanentes. Podrían citarse numerosos pasajes, pero baste con este bien elocuente: “... Con la punta del pie no me río, / más bien conservo mi dignidad, / y si me muevo por la escena lo hago como un excelente / [...] Así por la mañana o por la tarde / cuando llegan las multitudes yo saludo con el gesto, / y no les muestro el talón porque eso es una grosería. / Antes bien, les sonrío, les tiendo la mano, / dejo escapar un pensamiento, una mariposa irisada, / / mientras rubrico mi protesta convirtiéndome en estiércol". El poema al que pertenece este fragmento se titula, como una señal más de burla, "Con todo respeto"2.

Si hablamos en términos positivos, no sobre los valores que Aleixandre desde su poesía condena sino de aquellos otros que defiende y hace suyos, veremos que su "ideario" tiene por eje la libertad, entendida ésta de modo gozoso y sin censuras morales, defensora del eros primordial, de la pasión (aunque conduzca a veces a la destrucción) fuera de normas y convencionalismos. Es una libertad que entronca con ciertos mitos culturales del romanticismo, que repudia la ropa, los adornos y las joyas, como signos negativos de una civilización que nos aparta de la verdadera naturaleza ${ }^{3}$. Aleixandre en esta fase surrealista de su poesía, y aun antes, en su inicial y cristalino Ámbito (1928), se nos presenta como continuador de una tradición libertaria que tiene su arranque en el prerromanticismo y se mantiene luego durante la primera mitad del siglo XIX en autores como Saint-Simon, Rousseau o Charles Fourier. Sus ideas del amor-pasión, la fraternidad, el reconocimiento, encuentran sus raíces más próximas en ellos. Su concepción de la libertad, en este momento, retoma los ideales del anarquismo utópico frente a los imperativos y dogmas de una sociedad vuelta de espaldas a la naturaleza. 
No se piense que la actitud antisocial que Aleixandre muestra en su poesía de los años 30 es meramente teórica y que no guarda correspondencia alguna con su forma profunda de ser y de pensar por aquellas fechas. El sentimiento de repudio social está en él fuertemente arraigado y aflora en cuanto halla un interlocutor válido con el que desahogarse. A sus treinta y dos años, su gran amigo era -y lo fue hasta el fin de sus días- Dámaso Alonso, y a él le dirige la siguiente confidencia, en carta de 1 de agosto de 1930, cuando Vicente se encontraba con su familia en un balneario de Royat, en La Obernia francesa ${ }^{4}$ :

Lo que me revienta es [...] la sociedad frívola y majadera, para la que me siento hostil, del Hotel donde vivo. Yo no sé si es que me faltan dotes de efusión, que me voy secando, o es que ya soy más severo; pero es el caso que la tertulia después de la comida me hastía, que el intercambio de los menudos sentimientos o fórmulas me dejan frío, y que cada vez me siento menos hombre de sociedad. Esto a veces me apena. No soy lo suficientemente fuerte para "flagelarles", para manejar el látigo en la conversación como aquel Byron irresistible que hacía de un salón una jaula de bichos obedientes a su dominio. Ni soy uno de ellos que pueda del todo interesarme su intercambio. No me interesan ni como víctimas ni como pares. ¿Qué hacer?

Y más adelante, en la misma carta, esta otra reveladora y extraordinaria confesión que completa el retrato del poeta surrealista que Aleixandre era en $1930^{5}$ :

Si yo fuera un hombre fuerte, ahora estaría en Pekín o en la India. Pero no estaría aquí, conmigo, sino con el mundo, con lo externo, con lo que no soy yo. Por eso llevo en mí una actitud de protesta. Porque te advierto una cosa: que todo lo que es rebeldía, no conformidad, sea o virtud o vicio, tiene mi simpatía. La revolución y el crimen tienen a ratos mi mirada atenta, interesada.

La persona que escribe esto por carta al amigo es la misma que compone los poemas en prosa de Pasión de la Tierra, con su visión crítica de una sociedad en decadencia, fatua y aburrida, y para la que sólo tiene una mirada de desdén. Es la misma persona que escribe los versos, de un erotismo agresivo y rebelde, de Espadas como labios. Es este, en suma, el ideario -si no queremos hacer uso de la palabra ideología, más cargada de connotaciones políticas- de un hombre que comulga con los postulados inconformistas de Fourier y ve en el sabio retorno a la naturaleza, lejos de la polis, el camino de vuelta a la felici- 
dad. Esto es lo que era Vicente Aleixandre antes de la guerra del 36: un anarquista utópico.

Así lo supo ver atinadamente el poeta y crítico Guillermo Carnero en un temprano trabajo suyo, en el que se lee: "Anarquismo es el rótulo que habríamos de poner, desde un punto de vista político, a las ideas de Aleixandre acerca de la relación hombre-sociedad, tal como están formuladas poéticamente desde Ámbito" ". En este sentido, sorprende que alguien haya podido insinuar en fecha reciente que Aleixandre era un "señorito", y dicho esto con la mayor seriedad, tomando la palabra "señorito" "7 no como mera fórmula de uso social de tratamiento, que es lo que era en su caso, sino como un auténtico talante o manera de ser, afortunadamente ya desaparecida -creemos- en la España de hoy. Aquellos verdaderos "señoritos", clasistas, reaccionarios y caciquiles, que Antonio Machado inmortalizó en la figura de su don Guido, no tienen nada que ver con Aleixandre, un hombre que vivió, por el contrario, entregado a la comprensión de los otros con enorme tolerancia, atento, delicado y respetuoso.

\section{DON CIRILO ALEIXANDRE, REPRESALIADO}

La suerte que corrió Vicente Aleixandre durante la Guerra Civil no se puede entender bien si no atendemos a las vicisitudes vividas al mismo tiempo por su padre, don Cirilo Aleixandre Ballester, en aquellos trágicos años. Muerta la madre en 1934, vivían juntos en la casa de Velintonia, en el Parque Metropolitano de Madrid, el padre con sus dos hijos, Vicente y Conchita, un año menor que el hermano.

El poeta desde el primer momento, como ya se ha dicho, apoyó la causa republicana, aunque otro muy distinto debía de ser el sentimiento político que se respiraba en el ambiente familiar, pues su padre, hombre de derechas, con un puesto de responsabilidad en los Ferrocarriles Andaluces, católico practicante y militar retirado con el grado de coronel desde 1919, no bien se declara la guerra es represaliado por el Comité de Explotación de Ferrocarriles. Sobre los acontecimientos sobrevenidos a partir del 18 de julio pensaría de forma muy diferente a la de su hijo ${ }^{8}$.

Por los documentos conservados en los archivos de RENFE, hoy sabemos que don Cirilo Aleixandre fue suspendido de empleo y sueldo como ingeniero agregado a la Dirección de los Ferrocarriles Andaluces (zona Oeste), 
por orden del Ministerio de Obras Públicas del día 3 de agosto de 1936, y forzado a jubilarse por el Comité de Ferrocarriles que actuaba en Málaga el día 13 del mismo mes y año. Se le impone, además, una multa de quinientas pesetas, lo que era una cuantiosa sanción para la época, "por actos que afectan al orden público dirigidos a perturbar el funcionamiento de las instituciones del Estado legítimo", según palabras textuales del oficio que se le hizo llegar.

Por todas estas circunstancias se comprenderá que la vida en el seno de la familia Aleixandre debió de conocer tensiones y momentos de preocupación y malestar, pero la mucha estima que padre e hijo se tenían evitó cualquier distanciamiento entre ellos, e hizo posible que se sobrepusieran a la difícil situación y que encontraran una forma de convivir tolerante y respetuosa.

\section{ESPAÑOLETO, 16}

Hasta hace poco se creía que los tres miembros de la familia Aleixandre se fueron de la casa de Velintonia a Miraflores de la Sierra, a cuarenta y nueve kilómetros de Madrid, y que allí pasaron -véase la biografía de De Luisvarios meses de la guerra. La verdad es que la guerra les sorprendió estando ya en la casa de los veranos, "Vistalegre", en Miraflores de la Sierra. Se habían ido, como todos los años, a pasar allí las vacaciones. El día 11 de julio están ya en Miraflores $^{10}$, justo una semana antes del comienzo de la guerra. Pero la Sierra madrileña se vuelve un estratégico teatro de operaciones para la defensa de la capital, como describe en su minucioso estudio La batalla de $\mathrm{Ma}$ drid Jorge Martínez Reverte ${ }^{11}$. Pronto la Sierra de Guadarrama fue línea de permanentes conflictos. La inseguridad iba en aumento, en vista de lo cual la familia Aleixandre decidió volverse a Madrid, a Velintonia. Y allí estuvieron hasta que la zona del Parque Metropolitano, donde estaba y sigue estando enclavada la mítica casa del poeta, dejó de ser lugar seguro y no tuvieron más remedio que ir entonces a refugiarse a casa de su tío Agustín, hermano del padre, a la calle de Españoleto 16, en pleno centro del Madrid asediado. Esta vivienda era una "antigua casa madrileña", de varias plantas, todas ellas para la familia y, en la parte baja, un gran patio cerrado por donde se entraba a las cocheras y a otras dependencias que servían de guardamuebles y desván. En uno de esos habitáculos cerrados, casi sin luz natural, pasó gran parte de la guerra Vicente, a resguardo de los posibles peligros a los que estaba expuesto. 
Una persona muy próxima al poeta, cuya identidad me reservo, me confió por carta que prácticamente toda la guerra la pasó Vicente y su familia en la casa de Españoleto: al principio, en la vivienda familiar, en el piso superior, pero, tras su detención en los primeros meses de 1937 (enseguida pasamos a hablar de este incidente), prefirió protegerse de indiscretas miradas y trasladarse a uno de aquellos desvanes del patio, en la planta baja, sólo con luz eléctrica y escasa ventilación. Allí estuvo hasta el final de la contienda. Y allí recibió a algunos de sus amigos más allegados, como Pablo Neruda y Delia del Carril, Miguel Hernández y Carlos Pellicer, en cuya discreción podía confiar plenamente. También allí lo visitaron Rafael Alberti y $\mathrm{M}^{\mathrm{a}}$ Teresa León. En una espléndida estampa, años después, rememoraría Aleixandre el paso de todos ellos por Españoleto para interesarse por el amigo en obligado retiro ${ }^{12}$.

\section{LA DETENCIÓN}

Pocos detalles quiso facilitar Aleixandre sobre la detención de que fue objeto en los primeros meses del 37. En alguna carta a José Antonio Muñoz Rojas cuenta algo, pero más prefiriendo olvidar que revivir aquel desafortunado episodio y ahondar en pormenores. "iMolesta tanto -le confiesa al amigo- tener que recordar lo que uno quisiera olvidar definitivamente!"13 Nada dijo, por ejemplo, pese a su importancia, de los motivos de su detención. Serían muy probablemente circunstanciales, y tan poco razonables y comprensibles como los esgrimidos contra tantas otras personas denunciadas, víctimas inocentes que fueron barridas por la barbarie de la guerra. El mero hecho de acompañar a misa a su padre -él, que no era ni practicante ni creyente, pero que lo hacía por ofrecerle compañía y, hasta donde era posible, protección-, lo pudo convertir en "sospechoso", en supuesto simpatizante del mal llamado bando nacional, y aún más teniendo en cuenta que, por edad, en cualquier momento podía ser movilizado como soldado de reemplazo y llevado al frente. "Hasta la conclusión de la guerra -como recuerda James Matthews- se llamó a filas a chicos de dieciséis y a hombres maduros de cuarenta y cinco años." ${ }^{14}$ Vicente tenía treinta y ocho cuando fue detenido ${ }^{15}$.

La idea de que se tratara de un "emboscado" debió cobrar visos de verosimilitud cuando, registrada su casa de Velintonia, abandonada ya desde hacía meses, se descubre en un armario un uniforme militar. La orden de detención 
debió de producirse en ese mismo momento. Quien la dio ignoraba que aquel uniforme no era del poeta sino de su padre, que lo conservaba desde sus años de servicio al ejército como ingeniero militar de carrera ${ }^{16}$. Del abandono de la vida militar habían pasado diecisiete años, tantos como los que llevaba ejerciendo en la vida civil como ingeniero de la compañía de los Ferrocarriles Andaluces.

La misma fuente reservada que facilitó la información de que Vicente había pasado prácticamente toda la guerra en la casa familiar de Españoleto 16, me reveló también el apellido del oficial que ordenó detener al poeta (sólo conservaba memoria de su apellido): fue un teniente llamado Cantabrana, quien más tarde -y con la graduación de capitán- moriría en el frente. Hasta el momento poco se sabe de quién fuera ese teniente Cantabrana. En la documentación que se conservaba en el Archivo de la Guerra Civil, en Salamanca, hay varios militares republicanos con ese mismo o parecido apellido. A falta de pruebas concluyentes, no podemos saber a fecha de hoy quién fue el responsable de la detención ni los motivos oficialmente alegados. (Largo camino el que queda por recorrer en busca de datos y pruebas en los archivos militares de la Guerra Civil, hasta no hace mucho hermético campo de investigación.)

De la prisión militar sacó a Vicente, en menos de veinticuatro horas, su amigo Pablo Neruda, que residía por entonces en Francia, pero con gran poder de influencia en los medios republicanos a través de la Embajada de Chile. Y también contribuyó a su rápida excarcelación otro poeta amigo: Manuel Altolaguirre, que estaba en el ejército de tierra como impresor y difusor de propaganda republicana.

\section{EL APOYO A LA REPÚBLICA}

Hasta ese momento Aleixandre había colaborado, como es bien sabido, en revistas y diarios que defendían la causa popular: La voz, El mono azul, Hora de España, Les poètes du monde..., Unión de escritores y artistas revolucionarios, Mundo Obrero, Ahora... La lista podría ser más extensa porque los textos pasaban con celeridad de una publicación a otra con absoluta libertad. Nadie ponía la menor traba por tratarse de una causa que merecía toda la ayuda posible. Por esas revistas y periódicos circularon dos romances de Vicente Aleixandre ("El fusilado" y "El miliciano desconocido"), una traducción 
suya del francés de un poema de Nancy Cunard ("Para hacerse amar"), y un hermoso retrato en prosa de García Lorca, titulado escuetamente "Federico", escrito cuando trascendió la noticia de su asesinato. De todos los textos de aquel momento de combate, el más apasionado y revolucionario es sin duda su "Oda a los niños de Madrid muertos por la metralla", de gran valor no sólo propagandístico sino estético, a la altura de los mejores textos inspirados por el horror de la contienda, entre los que habría que citar "La muerte del niño herido" o "El crimen fue en Granada", de Antonio Machado, ciertos poemas de Miguel Hernández, España, aparta de mí este cáli», de César Vallejo, o la gran elegía "España, en el corazón”, de Pablo Neruda ${ }^{17}$.

Motivaron la escritura de esta "Oda" los bombardeos sobre la población civil madrileña, de los que tantas mujeres y niños fueron víctimas en la sangrienta jornada del 23 de octubre y en los primeros días de noviembre. "El 23 de octubre -recuerda el historiador Antony Beevor-, aviones Junker 52 bombardearon Getafe y, por primera vez, la ciudad de Madrid. De una cola de mujeres que intentaban comprar alimentos 'sólo quedan trozos de carne quemada, hacinamiento de cadáveres" $" 18$. La "Oda" no es propiamente una elegía, aunque también lo sea, sino sobre todo una arenga con un lenguaje inequívocamente revolucionario clamando venganza ante aquella masacre: "La ciudad alza un brazo terrible. / Un puño clamoroso, rojo de sangre libre, / que la ciudad esgrime, iracunda, y dispara". Ese puño rojo, que convoca a la muchedumbre al castigo de aquel crimen, fue el que le valió a Aleixandre en su ficha del bando insurgente, conservada en el Archivo General de la Guerra Civil, en Salamanca, la consideración de "Autor de una poesía de exaltación roja". Términos literales ${ }^{19}$.

Pero el apoyo de Aleixandre a la causa republicana no se limitó a textos poéticos. Intervino una noche al comienzo de la guerra en un meeting obrero al lado de Rafael Alberti y otros poetas, en la Estación del Norte de Madrid ${ }^{20}$. Prestó colaboración también fuera del ámbito de la poesía, con su firma o su dinero. Que sepamos, suscribió la petición promovida desde Barcelona para crear una gran editorial que sirviera a la educación de los jóvenes del bando republicano. Se adhieren a ella setenta intelectuales y poetas, entre ellos Jacinto Benavente, Antonio Machado, León Felipe, Octavio Paz, Rafael Alberti y María Teresa León, Luis Cernuda, Miguel Hernández y Manuel Altolaguirre² Firma también la carta de la Alianza de Intelectuales Antifascistas, publicada en Mundo Obrero, en la que se denuncia y condena "la patológica crueldad" 
del bando enemigo ${ }^{22}$. Asimismo, colaboró económicamente con los milicianos de la columna Torres-Benedito, bajo el control de la C. N. T. de Valencia, en octubre de $1936^{23}$.

Pero a partir de abril de 1937, cuando empezaba a prepararse el II Congreso Internacional de Escritores Antifascistas, Aleixandre suspende su colaboración con la República. No se le conoce ninguna colaboración más. Una supuesta recaída de su enfermedad renal le lleva a no participar más en las diversas antologías de la España leal. En nota adjunta a la edición de Valencia con motivo del citado Congreso se excusa la presencia de Aleixandre porque "enfermo en Madrid, ha tenido que suspender -se dice textualmente- su labor literaria y con ella el poema que dedicaba a esta colección" "24. Sólo romperá su silencio con la publicación del conmovedor retrato lírico "Federico", bellísima página a la que ya hemos aludido, y de la que llama poderosamente la atención un detalle: siendo como es un texto escrito en los momentos más duros del conflicto, no contiene ni una sola palabra de condena ni una alusión al asesinato de su querido amigo ni a los horrores de aquel momento histórico. Se diría un retrato escrito como desde una campana de cristal.

\section{HACIA EL EXILIO}

¿Qué es lo que ha ocurrido? Aleixandre, a pesar de su apoyo a la causa del pueblo, acababa de ser detenido y conducido a la cárcel por los militares de su propio bando. La guerra, con su irracionalidad, volvía a ser todo cuanto no se comprendía. A partir de ese momento, él se retiró y optó por el silencio. No podía hacer otra cosa si no estaba seguro ni con los suyos.

Esto debió de suceder en los primeros meses de 1937 (en torno a febrero o marzo de ese año). Desde entonces, su retracción es como un silencio que se deja oír. Para la marcha de la guerra y para Aleixandre, la situación se vuelve cada vez más crítica con el avance de las tropas franquistas, que no hacen prever ya un desenlace favorable al conflicto. A finales de 1937 o comienzos del 38, tras completar el ejército sublevado la conquista del norte peninsular, la balanza de la contienda empieza a inclinarse visiblemente a su favor. Como recuerda Beevor: "Hacia finales de 1937, los franquistas ya estaban en mucha mejor situación que los republicanos" 25 . Aún quedaban 
decisivas y sangrientas batallas, como la recuperación de Teruel por las tropas fascistas (febrero-abril del 38) o la batalla del Ebro (julio-noviembre del 38), pero la suerte de la guerra parecía prácticamente decidida.

Ante la perspectiva, bien real y amenazante, del triunfo de Franco, el poeta comprende que su situación es muy comprometida y que se expone a todo tipo de represalias si continúa en el Madrid asediado cuando el ejército enemigo entre en la capital y se haga con el control del poder. Era una cuestión de mera supervivencia. Sólo estaría a salvo si conseguía salir de España. Pensó entonces en marcharse a un sanatorio al sur de Francia, en la localidad de Pau, para que allí con buena alimentación, reposo y cuidado médico, pudiera restablecer su salud. Solicitó, pues, el permiso de salida, no sólo para él sino también para la hermana y su padre, que estaban dispuestos a acompañarle a ese azaroso exilio. La historia de aquella, sin duda, dolorosa decisión ya ha sido relatada con todo detalle y con la aportación de documentos nuevos y reveladores en el trabajo que mencioné al comienzo de estas páginas. Se explicaba allí -hago ahora una rápida síntesis- que Aleixandre solicitó a las autoridades de la República la salida de España a causa del recrudecimiento de la enfermedad renal que había padecido seis años antes. Pese al informe médico que aconsejaba la evacuación del enfermo ${ }^{26}$ y las cartas de apoyo presentadas desde la Casa del Pueblo de Valencia por Dámaso Alonso, Luis Cernuda y María Zambrano, el permiso para salir de España le fue denegado. No consideraban válido el certificado del doctor Francisco Rozabal, médico de la familia, al estar Vicente todavía en edad militar. Tenía que ser inexcusablemente un médico castrense el que lo reconociera para, con su aprobación, poder facilitarle (a él y a los suyos) el salvoconducto para salir del país.

\section{RAZONES DEL “EXILIO INTERIOR” (RESUMEN PROVISIONAL)}

Lo que podría haber sido un exilio voluntario, como el de tantos otros republicanos, se convirtió en el caso de Vicente Aleixandre en un exilio interior forzoso, obligado, al negarle las autoridades de la República, por los motivos ya expuestos, el permiso para viajar al extranjero. La secuencia cronológica para entender bien los acontecimientos sigue esta línea temporal: detención en febrero o marzo de 1937; informe médico para la evacuación, en octubre del mismo año; trámites ante el Ministerio de Instrucción Pública, en febrero-abril del 38; y rechazo de su solicitud, el 12 de abril del 38 . 
El intento frustrado de exiliarse Aleixandre no fue recogido por su biógrafo “oficial” Leopoldo de Luis en 1970, pero en cambio sí recogen esta noticia, años más tarde, entrados ya en la democracia, dos escritores próximos al poeta: José Luis Cano y Fernando Delgado. En 1981, Cano brinda así esta información: "Pablo Neruda, como cónsul de Chile, le propone llevarle en un avión a París para instalarle allí en un sanatorio donde podría cuidarse sin las amenazas de la guerra" 27 . Por su parte, Fernando Delgado, en la entrevista radiofónica que le hizo en 1982 -y luego transcrita para El País-, le pregunta por su actuación durante la Guerra Civil y Vicente Aleixandre reconoce que "en el año 1937 intenté marchar, pero no me dieron el permiso porque yo estaba en edad militar. Y luego, enfermo, no pude alejarme con los otros y me quedé aquí" ${ }^{28}$. El rechazo, pues, de las autoridades militares republicanas, a su salida del país, está en el origen, como razón primera, del exilio interior al que debió plegarse Aleixandre en aquellas duras circunstancias.

Pero inmediatamente acabada la guerra, otra razón se interpuso para retenerle en España. Y es que su padre, a las pocas semanas de finalizar la contienda, fue sometido a un proceso de depuración que duró meses y que mantuvo en vilo a toda la familia. El proceso, de más de siete meses de duración y sujeto a muchas tensiones, comenzó el día 15 de abril del 39 y finalizó el 20 de noviembre del mismo año. Sin tiempo de recuperarse del desgaste sufrido por la guerra, don Cirilo queda agotado por la exhaustiva investigación de que es objeto ${ }^{29}$. Vicente, en una carta a su amigo José Antonio Muñoz Rojas, le comenta sin ocultar sus temores lo siguiente: "Mi padre, el pobre, vive, pero ha envejecido enormemente, de modo que me preocupa y acongoja" ${ }^{30}$. Maltrecho de salud como estaba, don Cirilo Aleixandre falleció tres meses después de haber sido rehabilitado y readmitido en su cargo al frente de los Ferrocarriles Andaluces ${ }^{31}$.

Mientras tanto, el poeta, que se había visto obligado a llevar una vida de reposo, aislado en los bajos de la casa familiar, cuando acaba la guerra y reinicia su vida, toma una determinación tajante: la de renunciar a todo tipo de actividad pública como rechazo al régimen franquista. Su forma de disidencia fue la de mostrarse permanentemente como un enfermo, más como malade imaginaire que como enfermo de consideración, a fin de no tener que colaborar bajo ningún concepto con el bando ganador. Muy elocuente resulta en este sentido la anécdota que recoge José Luis Cano en Los cuadernos de Velintonia, cuando en 1973 algunos académicos propusieron su candida- 
tura para el Premio Nobel. Ante la eventualidad de que el gobierno de entonces quisiera apuntarse un tanto y explotar el premio a su favor, Aleixandre reacciona con indignación: "Espero - dice a su amigo y confidente- mantener mi independencia en este asunto, y no tener que deber nada al Régimen, y me negaré a homenajes oficiales". Y añade, en tono de amenaza: "Me meteré en la cama y diré que estoy enfermo para eludirlos."32

Es cierto que arrastró durante toda su vida problemas de salud de muy diversa índole, pero una enfermedad seria no volvió a aquejarle desde que le extirparon en 1932 el riñón derecho, el único afectado por la tuberculosis. Su riñón salvado debía de estar lo suficientemente sano como para no necesitar, durante una vida larga como la suya, de especiales cuidados nefrológicos. Desde luego la causa de su muerte no estuvo provocada por una nefrosis ${ }^{33}$.

La enfermedad, en su caso, fue no sólo el motivo para intentar salir del Madrid asediado sino que, después, se valió de ella para quedar al margen durante la posguerra de cualquier actividad que lo vinculara con la dictadura. Su retracción de hombre enfermo tuvo mucho de deliberada oposición. Su disidencia fue esa: el retraimiento de toda actividad pública oficial como manera de salvaguardar su independencia, como intelectual y como poeta. Al permanecer en España, manteniendo vivo el espíritu de libertad y tolerancia en el que se había formado el Grupo del 27, se convirtió en el punto de referencia más visible de una historia que para muchos estaba lejos de haber concluido. Vicente Aleixandre, desde ese "exilio interior", representaba no el pasado sino el presente de aquel pasado, su salvadora pervivencia. Era la continuidad de una España que, pese a todo, había sobrevivido.

\section{NOTAS}

1 Las actas de aquel congreso se acabaron publicando en Roma, por Antonio Pellicani Editore, en 2001, al cuidado de Francesco Saverio Festa y Rosa Maria Grillo. Mi intervención se recogió también en el volumen colectivo Trespoetas, tres amigos, Murcia, CajaMurcia, Obra Cultural, 1999 (Francisco Javier Díez de Revenga y Mariano de Paco eds.), pp. 49-63.

2 V. Aleixandre, Poesías completas, Madrid, Visor, 20053, p. 307 (A. Duque Amusco ed.).

4 Cf. C. Bousoño, La poesía de Vicente Aleixandre, Madrid, Gredos, 19775, pp. 45-68, y V. Granados, La poesía de Vicente Aleixandre (Formación y evolución), Málaga, Planeta, 1977, pp. 179-180. 
6 V. Aleixandre, Prosas completas, Madrid, Visor, 2002, pp. 739-740 (A. Duque Amusco ed.).

7 Ibid., pp. 739-40.

8 G. Carnero, “Ámbito (1928): Razones de una continuidad”, Cuadernos Hispanoamericanos 352-354, 1979, p. 391.

9 Vid. I. Emiliozzi, "Introducción" a las Cartas de Vicente Aleixandre a José Antonio Muñoz Rojas, Valencia, Pre-Textos, 2005, especialmente pp. 21-22.

10 Toda la información acerca de don Cirilo Aleixandre y sus avatares durante la guerra e inmediatamente después proceden de los archivos de RENFE, a los que accedí gracias a la colaboración de Gonzalo García Sánchez, "Garcival”, periodista especializado en tema ferroviario, al que desde aquí expreso mi reconocimiento.

11 Leopoldo de Luis, Vicente Aleixandre, Madrid, EPESA, 1970, p. 113. También en la reedición ampliada Vida y obra de Vicente Aleixandre, Madrid, Espasa-Calpe, 1978, p. 138.

12 Ramón Fernández Palmeral, "Vicente Aleixandre y Miguel Hernández: una leal amistad" (www.letralia.com/166/articulo01.htm) [10 octubre 2012].

13 J. M. Reverte, La batalla de Madrid, Barcelona, Crítica, 2004, pp. 81-215.

14 "La última vez que vi a Pablo Neruda", en Prosas completas, ya cit., pp. 655-658.

15 Op. cit., pág. 112.

16 J. Matthews, "Moral y motivación de los movilizados forzosos del Ejército Popular de la República en la Guerra Civil Española 1936-1939”, en Studia historica. Historia contemporánea, 24, Ediciones Universidad de Salamanca, 2006, p. 85.

17 Oportuno resulta, llegados a este punto, el testimonio de José Moreno Villa sobre los pasos que hubo de dar en el otoño de 1936 para estar localizable y a disposición del Ejército: “. . . bajé a la Castellana -recuerda Moreno Villa-y penetré en un edificio grande y rojo -la Escuela de Sordomudos-, donde a la sazón se inscribía uno para el servicio militar. Hice cola, di mis datos y quedaron en avisarme. A los pocos días recibí una carta diciéndome que me llamarían cuando fuese necesario. Yo estaba por cumplir los cuarenta y nueve años". Vida en claro, México, Fondo de Cultura Económica, 19762, p. 107.

18 Información vertida por el poeta en carta a su amigo Muñoz Rojas el 26 de mayo de 1939 (vid. Cartas de Vicente Aleixandre a José Antonio Muñoz Rojas, ya cit., p. 108).

19 Para la procedencia de los diversos textos "de combate" de Vicente Aleixandre, remitimos a la sección Historia editorial de sus Poesías completas (2001), pp. 1540-41 y 1565.

20 A. Beevor, La guerra civil española, Barcelona, Crítica, 2005, p. 255.

21 La ficha de Vicente Aleixandre llevaba en junio del año 2000, época en que realizamos la consulta, la siguiente signatura: Leg. L. 1866.- Fol. 7.- Santander “L” Caja. 282.

22 R. Alberti, “Alta y personalísima poesía”, El País, 13 dic. 1984, suplem. "La Cultura”, p. 23.

23 Archivo General de la Guerra Civil española, Salamanca; signatura: P. S. Barcelona. Carp. 836. Fol. 310. (Lámina 1 del Apéndice, al final de este trabajo.) 
24 Mundo Obrero, Madrid, 19 noviembre 1936, reverso abajo. La carta va firmada, entre otros, por José Bergamín, Manuel Altolaguirre, Luis Cernuda, Miguel Hernández, Rodolfo Halffter, María Teresa León y Rafael Alberti, Emilio Prados y Arturo Serrano Plaja. (Se reproduce en Lámina 2 del Apéndice y se transcribe a continuación eliminando las erratas, inevitables, por la premura con que se imprimía.)

25 Archivo General de la Guerra Civil española, Salamanca; signatura: S.M. Caja 403. Fol. 75. (Se reproduce en Lámina 3, en el Apéndice.)

26 VV. AA., Poetas en la España leal, Madrid-Valencia, Ediciones Españolas, 1937, s. p. [=155] (ed. facsímil en Renacimiento, Sevilla, 2008, al cuidado de Manuel Aznar Soler).

27 A. Beevor, Op. cit., p. 463.

28 El informe emitido por el doctor Francisco Rozabal está fechado en Madrid el día 28 de octubre de 1937.

29 J. L. Cano, Vicente Aleixandre, Madrid, Ministerio de Cultura, colec. "España, escribir hoy", 1981, p.11.

30 F. Delgado, "El Nobel que he recibido es el dolor y el sufrimiento", en Prosas completas, ya cit., p. 981.

31 Información extraída del archivo de RENFE, remitimos a la nota 8.

32 Cartas de Vicente Aleixandre..., ya cit., pág. 108.

33 Don Cirilo Aleixandre Ballester murió en Madrid el 9 de marzo de 1940, a la edad de 74 años.

34 J. L. Cano, Los cuadernos de Velintonia, Seix Barral, Barcelona, 1986, p. 204.

35 Vicente Aleixandre falleció en la Clínica de Santa Elena, en Madrid, la noche del 13 de diciembre de 1984, a los 86 años de edad, a consecuencia de una hemorragia intestinal por la que poco se pudo hacer pese a la rápida intervención para contenerla.

\section{REFERENCIAS BIBLIOGRÁFICAS}

AbelLán, J. L. 1983. De la Guerra Civil al exilio republicano (1936-1977). Madrid: Mezquita. Abellán, J. L. 2000. El exilio español de 1939. Madrid: Taurus.

Aleixandre, V. 2001, 2005². Poesías completas. Madrid: Visor (Duque Amusco, A. ed.). Aleixandre, V. 2002. Prosas completas. Madrid: Visor (Duque Amusco, A. ed.).

BeEvor, A. 2005. La guerra civil española. Barcelona: Crítica.

Bousoño, C. 1977. La poesía de Vicente Aleixandre. Madrid: Gredos.

CANO, J. L. 1981. Vicente Aleixandre. Madrid: Ministerio de Cultura, colec. España, escribir hoy.

- 1986. Los cuadernos de Velintonia. Seix Barral: Barcelona.

Carnero, G. 1979. “Ámbito (1928): Razones de una continuidad”, Cuadernos Hispanoamericanos 352-354: 384-393.

Duque Amusco, A. 1999. "Vicente Aleixandre: el imposible exilio", en Díez de Revenga, F. J. y De Paco, M. (coords.). Tres poetas, tres amigos. Murcia: CajaMurcia Obra Cultural, 
49-63. También reproducido en Saverio Festa, F. y Maria Grillo, R. (coords.). La Spagna degli anni'30 di fronte all'Europa. Roma: Antonio Pellicani Editore, 2001, 285-297.

EMILIOZZI, I. 2005. "Introducción” a las Cartas de Vicente Aleixandre a José Antonio Muñoz Rojas (1937-1984). Valencia: Pre-Textos (transcripción y colaboración de Martínez Pereira, $\mathrm{M}^{\mathrm{a}}$ del C.).

Granados, V. 1977. La poesía de Vicente Aleixandre (Formación y evolución). Málaga: Planeta.

López CAmpillo, E. 1980. "Dictaduras e intelectualidad en el siglo XX en España", Asociación Internacional de Hispanistas. Actas 1980: 707-715.

M. Reverte, J. 2004. La batalla de Madrid. Barcelona: Crítica.

MARINelo, J. y Guillén, N. 2010. Hombres de la España leal [1938]. Sevilla: Renacimiento (Prólogo de Domingo Cuadriello, J.).

Mattheiws, J. 2006. "Moral y motivación de los movilizados forzosos del Ejército Popular de la República en la Guerra Civil Española 1936-1939”, Studia historica. Historia contemporánea 24: 81-105.

Moreno Villa, J. 1976². Vida en claro. México: Fondo de Cultura Económica.

Osuna, R. 1987. Pablo Neruda y Nancy Cunard. Madrid: Orígenes.

SALAÜN, S. 1985. La poesía de la guerra de España. Madrid: Castalia.

VV. AA. 1937. Crónica general de la Guerra Civil. Madrid: Ediciones de la Alianza de Intelectuales Antifascistas (ed. facsímil: 2007, Esteve, L. A. [ed.], Renacimiento: Sevilla).

VV. AA. 1937. Poetas en la España leal. Madrid-Valencia: Ediciones Españolas (ed. facsímil: 2008. Soler, M. A. [ed.], Renacimiento: Sevilla). 


\section{APÉNDICE}

\section{F.310- POR UNA GRAN EDITORIAL PARA LA \\ EDUCACION DE LA JUVENTUD}

La juventud española se dispone a crear su Editorial. Una Editorial, que atenderá cumplidamente a todas sus necesidades espirituales, uniendo en sus realizaciones, a las exigencias del presente, la preparación justa de un futuro más digno por el que hoy combate.

Nosotros, intelectuales, que luchamos al lado del pueblo, por la libertad de nuestra patria y por la defensa de su cultura, hemos seguido emocionados desde el primer día ef heroico esfuerzo de esta juventud incomparable que, bajo ningún pretexto, ni en ningún momento, ha escatimado su sangre valerosa, que se ha batido antes y aún sigue batiéndose en primeras líneas, defendiendo nuestra cultura y nuestro suclo en las graves horas porque nuestro país atraviesa.

Hoy vemos cómo sin abandonar su puesto en la guerra, nace en esta admirable juventud un nuevo deseo, que una vez más nos enseña la inquietud espiritual en que se mueve. Con él se aumenta nuestra fe, nuestra seguridad en clla, pero también se hace mayor la responsabilidad que contraemos.

La juventud crea su Editorial, en la cual, busca los medios nesesarios para el desarrollo y cultivo de su inteligencia: Todo cuanto pucda facilitar la formación intelectual y espiritual del hombre futuro.

Por esta juventud, de la que todo español se enorgullece merecidamente, levantamos nuestra voz, para pedir ayuda eficaz al enorme esfuerzo que representa el crear hoy. una Editorial de esta amplitud, en medio de las dificultades que la guerra impone.

Ayuda material, ayuda económica, ayuda espiritual exige de nosotros una juventud que en las horas de mayor peligro, no ha regateado ninguno. de los medios para salvar nuestra propia inteligencia.

Intelectuales, hombres libres de España, no olvidéis que su sangre sigue derramnándose sobre nuestros campos.

\footnotetext{
Jacinto Benavente. - Antonio Zozaya. - Enrique Diez Canedo.-Dr. Manuel Hárquez. - Tomás Navarro Tomás. -Antonio Machado.-León-Felipe.-José Puche.-Dr. Madinaveitia.-Virtorio Macho.Dr. Sacristán. - José Ciral. - Corpus Barga. - Arturo Duperier. - Bartolomé Pérez Casas. - Aurelio Arteta. - - Juan de la Encinas. -Dr. Miguel Prado Such. - Alberto. -josé Cuatrecasas. - Pedro Carrasco.-Manuel Sánchez Arcus.-Eduardo M. Torner.-José María Ots.-Angel Gans.-Salvador Bacarisse.-José Renau.-Rodolfo Halfier.-Timoteo Pérez Rubio.-Agustín Millares.-Juan Marinello.-Nicolás Guillén.-Mancisidor,-Andrés Iduarte.-Octavio Paz.-Juan de la Cabada.-CEsur W. Aronarda.Gabriel García Maroto.-Arturo Souto.-Rafael Alberti.-José Bergamín.-Emilio Prados.-Luis Cernuda. -Miguel Hernández. - Manuel Altolaguirre. - Vicente Alcixundre.- Eduardo Ugarte. - Arturo Serrano Plaja. - Manuel Angeles Ortiz. -María Teresa León. -María Zambrano. - I, tuis Lacasa.Juan Gil-Albert.-Miguel Prieto.-Mauricio Amster.-Ramón Gaya.-Ramón l'uyol.- Hortelano.Eduardo Vicente. -José Bardasano. - Pedro Garfias.-Juan Ficens.-José Ilerrera Petere.-Lino Novas Calvo.-A. Rodríguez Aldave.-A. Rodriguez Moñino.-Lorenzo Varela.-Antonio Aparicio.-Pérez Infante.-Emilio Delgado.
}

\section{LÁMINA 1}

Documento firmado por Vicente Aleixandre y otros intelectuales republicanos apoyando la creación de una Editorial para la juventud.

[Archivo de la Guerra Civil Española en Salamanca: P. S. BARCELONA. Carp. 836. Fol. 310] 


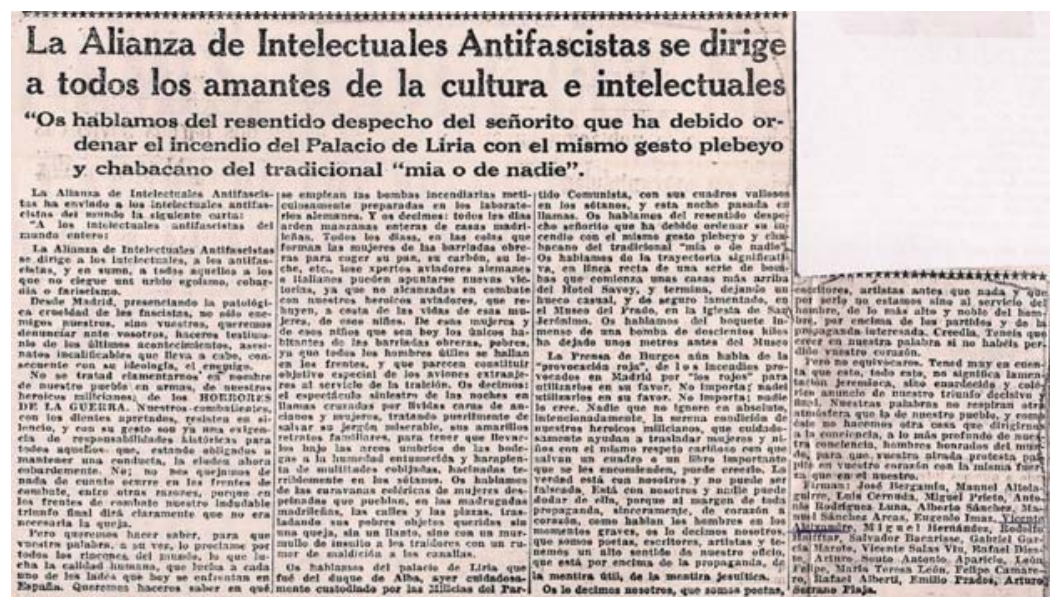

\section{LÁMINA 2}

Carta "A los intelectuales antifascistas del mundo entero", aparecida en Mundo Obrero, Madrid, jueves 19 de noviembre de 1936. Cuarta época. Núm. 278 (988). Entre otras muchas firmas, aparece la de V. Aleixandre. 


\section{[TRANSCRIPCIÓN DE LA CARTA A LOS INTELECTUALES ANTIFASCISTAS]}

A los intelectuales Antifascistas del mundo entero:

La Alianza de Intelectuales Antifascistas se dirige a los Intelectuales, a los antifascistas y, en suma, a todos aquellos a los que no ciegue un turbio egoísmo, cobardía o fariseísmo.

Desde Madrid, presenciando la patológica crueldad de los fascistas, no sólo enemigos nuestros, sino vuestros, queremos denunciar ante vosotros, haceros testimonio de los últimos acontecimientos, asesinatos incalificables que lleva a cabo, consecuente con su ideología, el enemigo.

No se trata de lamentarnos en nombre de nuestro pueblo en armas, de nuestros heroicos milicianos, de los HORRORES DE LA GUERRA. Nuestros combatientes, con los dientes apretados, resisten en silencio, y con su gesto son ya una exigencia de responsabilidades históricas para todos aquellos que, estando obligados a mantener una conducta, la eluden ahora cobardemente. No; no nos quejamos de nada de cuanto ocurre en los frentes de combate, entre otras razones, porque en los frentes de combate nuestro indudable triunfo final dirá claramente que no era necesaria la queja.

Pero queremos hacer saber, para que vuestra palabra, a su vez, lo proclame por todos los rincones del mundo, lo que lucha la calidad humana, a cada uno de los lados que hoy se enfrentan en España. Queremos haceros saber en qué se emplean las bombas incendiarias meticulosamente preparadas en los laboratorios alemanes. Y os decimos: todos los días arden manzanas enteras de casas madrileñas. Todos los días, en las colas que forman las mujeres de las barriadas obreras para coger su pan, su carbón, su leche, etc., los expertos aviadores alemanes e italianos pueden apuntarse nuevas victorias, ya que no alcanzadas en combate con nuestros heroicos aviadores, que rehúyen, a costa de las vidas de esas mujeres, de esos niños. De esas mujeres y de esos niños que son hoy los únicos habitantes de las barriadas obreras, pobres, ya que todos los hombres útiles se hallan en los frentes, y que parecen constituir objetivo especial de los aviones extranjeros al servicio de la traición. Os decimos: el espectáculo siniestro de las noches en llamas cruzadas por lívidas caras de ancianos y mujeres, tratando puerilmente de salvar su jergón miserable, sus amarillos retratos familiares, para tener que llevarlos bajo los arcos umbríos de las bodegas a la humedad entumecida y harapienta de multitudes cobijadas, hacinadas terriblemente en los sótanos. Os hablamos de las caravanas coléricas de mujeres despeinadas que pueblan, en las madrugadas madrileñas, las calles y las plazas, trasladando sus pobres objetos queridos sin una queja, sin un llanto, sino con un murmullo de insulto a los traidores, con un rumor de maldición a los canallas.

Os hablamos del palacio de Liria que fue del duque de Alba, ayer cuidadosamente custodiado por las Milicias del Partido Comunista, con sus cuadros valiosos en los sótanos, y esta noche pasada en llamas. Os hablamos del resentido despecho 
señorito que ha debido ordenar su incendio con el mismo gesto plebeyo y chabacano del tradicional "mía o de nadie". Os hablamos de la trayectoria significativa, en línea recta, de una serie de bombas que comienza unas casas más arriba del Hotel Saboy, y termina, dejando un hueco casual, y de seguro lamentado, en el Museo del Prado, en la Iglesia de San Jerónimo. Os hablamos del boquete inmenso que una bomba de doscientos kilos ha dejado unos metros antes del Museo.

La Prensa de Burgos aún habla de la "provocación roja", de los incendios provocados en Madrid por "los rojos" para utilizarlos en su favor. No importa; nadie lo cree. Nadie que no ignore en absoluto, intencionadamente, la serena condición de nuestros heroicos milicianos, que cuidadosamente ayudaban a trasladar mujeres y niños con el mismo respeto cariñoso con que salvan un cuadro o un libro importante que se les encomienden, puede creerlo. La verdad está con nosotros y no puede ser falseada. Está con nosotros y nadie puede dudar de ella, porque al margen de toda propaganda, sinceramente, de corazón a corazón, como hablan los hombres en los momentos graves, os lo decimos nosotros, que somos poetas, escritores, artistas y tenemos un alto sentido de nuestro oficio, que está por encima de la propaganda, de la mentira útil, de la mentira jesuítica.

Os lo decimos nosotros, que somos poetas, escritores, artistas antes que nada y que por serlo no estamos sino al servicio del hombre, de lo más alto y noble del hombre, por encima de los partidos y de la propaganda interesada. Creedla. Tenéis que creer en nuestra palabra si no habéis perdido vuestro corazón.

Pero no equivocaros. Tened muy en cuenta que esto, todo esto, no significa lamentación jeremíaca, sino enardecido y colérico anuncio de nuestro triunfo decisivo y final. Nuestras palabras no respiran otra atmósfera que la de nuestro pueblo, y, como éste, no hacemos otra cosa que dirigirnos a la conciencia, a lo más profundo de vuestra conciencia, hombres honrados del mundo, para que vuestra airada protesta palpite en vuestro corazón con la misma fuerza que en el nuestro.

Firman:

José Bergamín, Manuel Altolaguirre, Luis Cernuda, Miguel Prieto, Antonio Rodríguez Luna, Alberto Sánchez, Manuel Sánchez Arcas, Eugenio Imaz, Vicente Aleixandre, Miguel Hernández, Rodolfo Halffer, Salvador Bacarisse, Gabriel García Maroto, Vicente Salas Viu, Rafael Dieste, Arturo Souto, Antonio Aparicio, León Felipe, María Teresa León, Felipe Camarero, Rafael Alberti, Emilio Prados, Arturo Serrano Plaja.

(Mundo Obrero, Madrid, jueves 19 noviembre 1936.) 


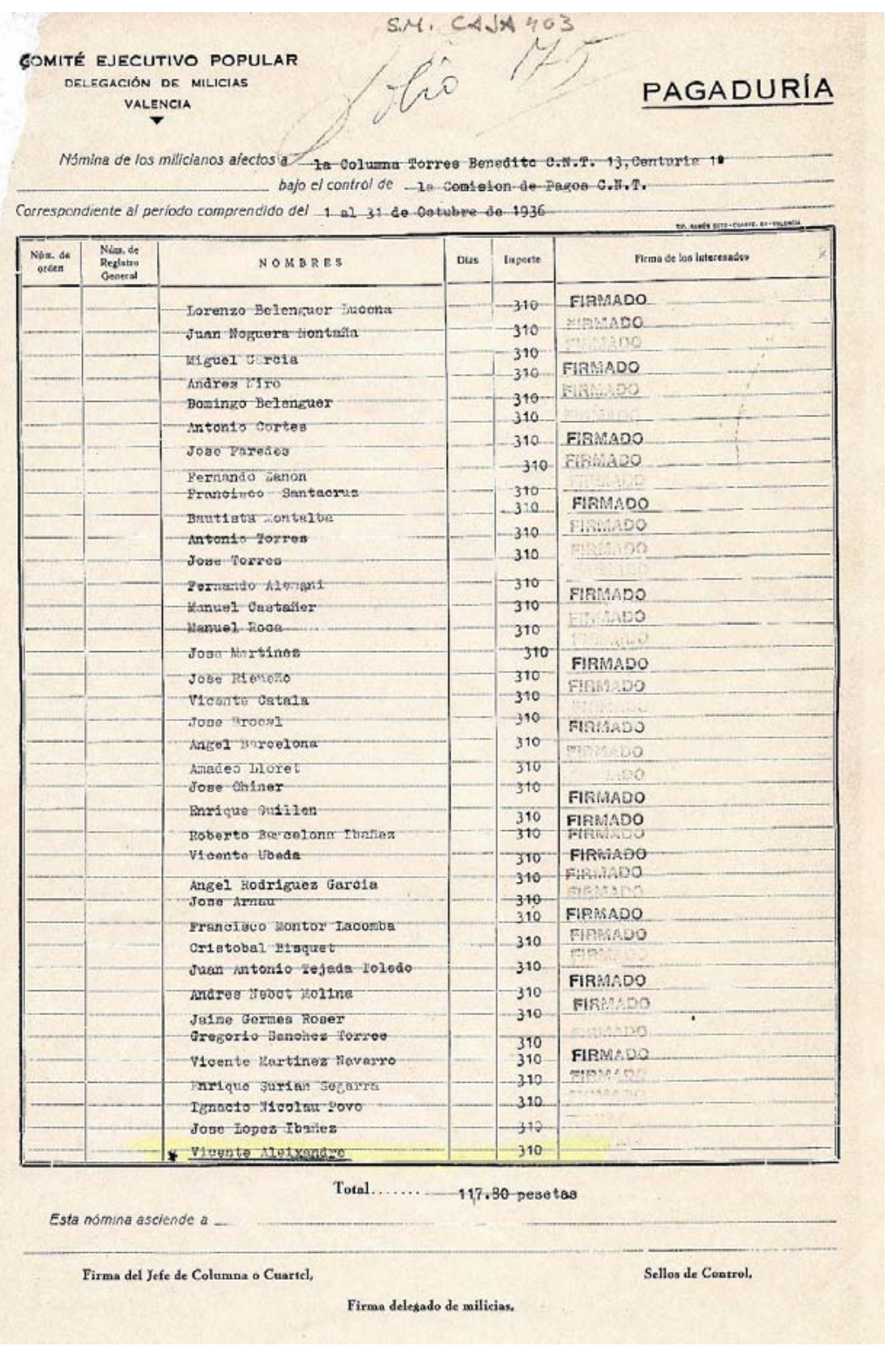

\section{LÁMINA 3}

Documento con las aportaciones económicas a la Columna Torres-Benedito, bajo el control de la C.N.T. de Valencia. Octubre de 1936. [Archivo de la Guerra Civil española, en Salamanca: S. M. Caja 403. Folio 175. 
